ARTICLE

DOI: $10.1038 / \mathrm{s} 41467-018-04277-7$

\title{
Silicon-oriented regio- and enantioselective rhodium-catalyzed hydroformylation
}

\author{
Cai You ${ }^{1}$, Xiuxiu Li ${ }^{1}$, Yuhong Yang ${ }^{2}$, Yu-Sheng Yang ${ }^{1}$, Xuefeng Tan ${ }^{2}$, Shuailong Li ${ }^{1}$, Biao Wei ${ }^{1}$,
} Hui Lv (D) ${ }^{1,3}$, Lung-Wa Chung (1) ${ }^{2} \&$ Xumu Zhang ${ }^{1,2}$

Hydroformylation of 1,2-disubstituted alkenes usually occurs at the $\alpha$ position of the directing heteroatom such as oxygen atom and nitrogen atom. By contrast, to achieve hydroformylation on the $\beta$ position of the heteroatom is a tough task. Herein, we report the asymmetric rhodium-catalyzed hydroformylation of 1,2-disubstituted alkenylsilanes with excellent regioselectivity at the $\beta$ position (relative to the silicon heteroatom) and enantioselectivity. In a synthetic sense, we achieve the asymmetric hydroformylation on the $\beta$ position of the oxygen atom indirectly by using the silicon group as a surrogate for the hydroxyl. Density functional theory (DFT) calculations are carried out to examine energetics of the whole reaction path for Rh/YanPhos-catalyzed asymmetric hydroformylation and understand its regioselectivity and enantioselectivity. Our computational study suggests that the silicon group can activate the substrate and is critical for the regioselectivity.

\footnotetext{
${ }^{1}$ Key Laboratory of Biomedical Polymers of Ministry of Education \& College of Chemistry and Molecular Sciences, Wuhan University, Wuhan, 430072 Hubei, People's Republic of China. ${ }^{2}$ Department of Chemistry, Southern University of Science and Technology, Shenzhen, 518055 Guangdong, People's Republic of China. ${ }^{3}$ Engineering Research Center of Organosilicon Compounds \& Materials, Ministry of Education, College of Chemistry and Molecular Sciences, Wuhan University, Wuhan, 430072 Hubei, People's Republic of China. These authors contributed equally: Cai You, Xiuxiu Li. Correspondence and requests for materials should be addressed to H.L. (email: huilv@whu.edu.cn) or to L.-W.C. (email: oscarchung@sustc.edu.cn)

or to X.Z. (email: zhangxm@sustc.edu.cn)
} 
$\mathrm{O}$ wing to the high atom economy, asymmetric hydroformylation (AHF) of alkenes provides an efficient way for the synthesis of enantiomerically pure aldehydes, which are versatile chiral intermediates for pharmaceuticals, agrochemicals, and other fine chemicals ${ }^{1-5}$. In the past decades, intensive research efforts have been made in this area, and a range of chiral phosphorus ligand systems have been developed for AHF reactions, including BINAPHOS ${ }^{6-8}$, bis(diazaphospholane) (BDP $)^{9-12}$, Chiraphite ${ }^{13}$, Ph-BPE ${ }^{14}$, YanPhos ${ }^{15-19}$, and other phosphorus ligands ${ }^{20-30}$. Many simple terminal alkenes have been converted into chiral aldehydes with practical levels of regioand enantioselectivity by AHF. However, for 1,2-disubstituted alkenes, the control of regioselectivity is a preeminent challenge because of the less steric difference between two substituent groups than in monosubstituted or 1,1-disubstituted alkenes. To date, only very limited examples have been reported in AHF of 1,2-disubstituted alkenes. To address this issue, Tan et al. designed the scaffolding catalysis for allyl amines and alcohols ${ }^{20}$, Reek et al. used the supramolecular catalysis in AHF of unactivated disubstituted olefins ${ }^{27}$, and in terms of the substrate design, Landis et al. successfully achieved AHF of 1,2-disubstituted alkenes comprising $(Z)$-enol esters and enamides with $\mathrm{Rh}-\mathrm{BDP}$ catalysts ${ }^{11}$. Due to electron-withdrawing groups, high regioselectivities were given (up to >99:1) for AHF of $(Z$ )-enol esters and enamides. The results suggest that the electronic and steric differentiation of the substituent groups is a key factor for the regioselectivity of this transformation. In these examples, $\mathrm{CO}$ was mainly incorporated at the a position of the oxygen atom or nitrogen atom (Fig. 1a) $)^{9-11,31-34}$. By contrast, to achieve the AHF on the $\beta$ position of the heteroatom $(\mathrm{O}$ or $\mathrm{N})$ is a tough task. Herein, we attempted to use the silicon group as a surrogate for the hydroxyl (via Fleming-Tamao oxidation ${ }^{35}$ ) in a synthetic sense, and the $\beta$ aldehyde product is more favorable due to the steric hindrance of the silicon group (Fig. 1b) ${ }^{36,37}$, which achieves the AHF on the $\beta$ position of the oxygen atom indirectly. Based on these ideas, a series of 1,2-disubstituted alkenylsilanes were designed and $Z$-alkenes were chosen instead of $E$-alkenes because of higher regio- and enantioselectivities and faster rates ${ }^{7,11}$.

Organosilicon compounds are essential synthetic reagents and intermediates in modern organic synthesis, and the Si atom itself

a

Asymmetric hydroformylation on the $\alpha$ position of the heteroatom ( $\mathrm{N}$ or $\mathrm{O}$ )

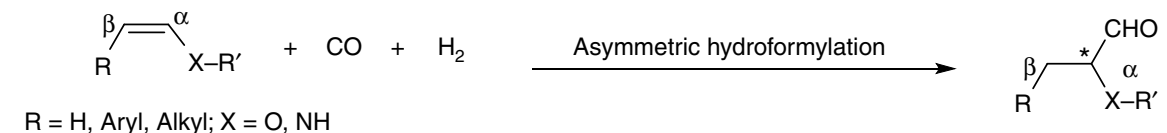$$
\mathrm{R}^{\prime}=\mathrm{Ac}, \mathrm{Bz}
$$

b

Asymmetric hydroformylation on the $\beta$ position of the silicon group (this work)

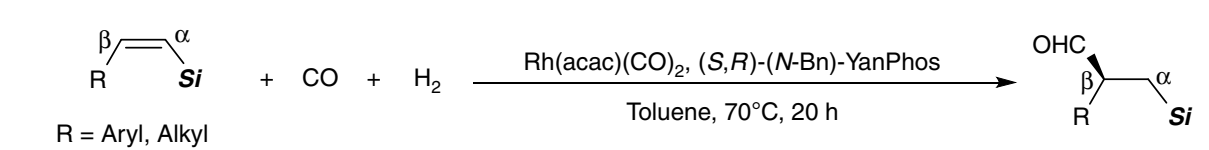

C<smiles>C[C@H](C[Si](O)(O)[C@H](Cc1ccccc1)NC(=O)c1ccccc1)C(=O)N1CCC[C@H]1C(=O)O</smiles>

A ACE inhibitor<smiles>O=C(N[C@H]1c2ccccc2C[C@H]1O)[C@H](Cc1ccccc1)C[Si](O)(O)C[C@@H](Cc1ccccc1)C(=O)N[C@H]1c2ccccc2C[C@H]1O</smiles>

B HIV protease inhibitor<smiles>CCCCOC(=O)[C@H](C)NC(=O)[C@H](CSC(C)=O)Cc1ccc2c(c1)OCO2</smiles>

C Fasidotril<smiles>CCN(Cc1ccncc1)C(=O)[C@H](CO)c1ccccc1</smiles>

F Tropicamide<smiles>COCCOC[C@H](CC1(C(=O)N[C@H]2CC[C@H](C(=O)O)CC2)CCCC1)C(=O)Oc1ccc2c(c1)CCC2</smiles>

D Candoxatril<smiles>CN1C(=O)C2C[C@H](OC(=O)[C@H](CO)c3ccccc3)C[C@@H]1C2</smiles>

G Scopolamine<smiles>COc1ccc([C@@H](CN(C)C)C2(O)CCCCC2)cc1</smiles>

E Venlafaxine<smiles>CN1C2C[C@H](OC(=O)[C@@H](CO)c3ccccc3)C[C@@H](C1O)[C@H]2O</smiles>

H Anisodamine

Fig. 1 Design of a asymmetric hydroformylation on the $\beta$ position of the heteroatom. a The $\alpha$ regioselectivity is controlled by electron-withdrawing inductive effects. $\mathbf{b}$ To achieve $\beta$ regioselectivity by a hindered silicon group. c Structures of biologically active compounds and natural products containing derivatives of $\beta$-aldehydesilanes 


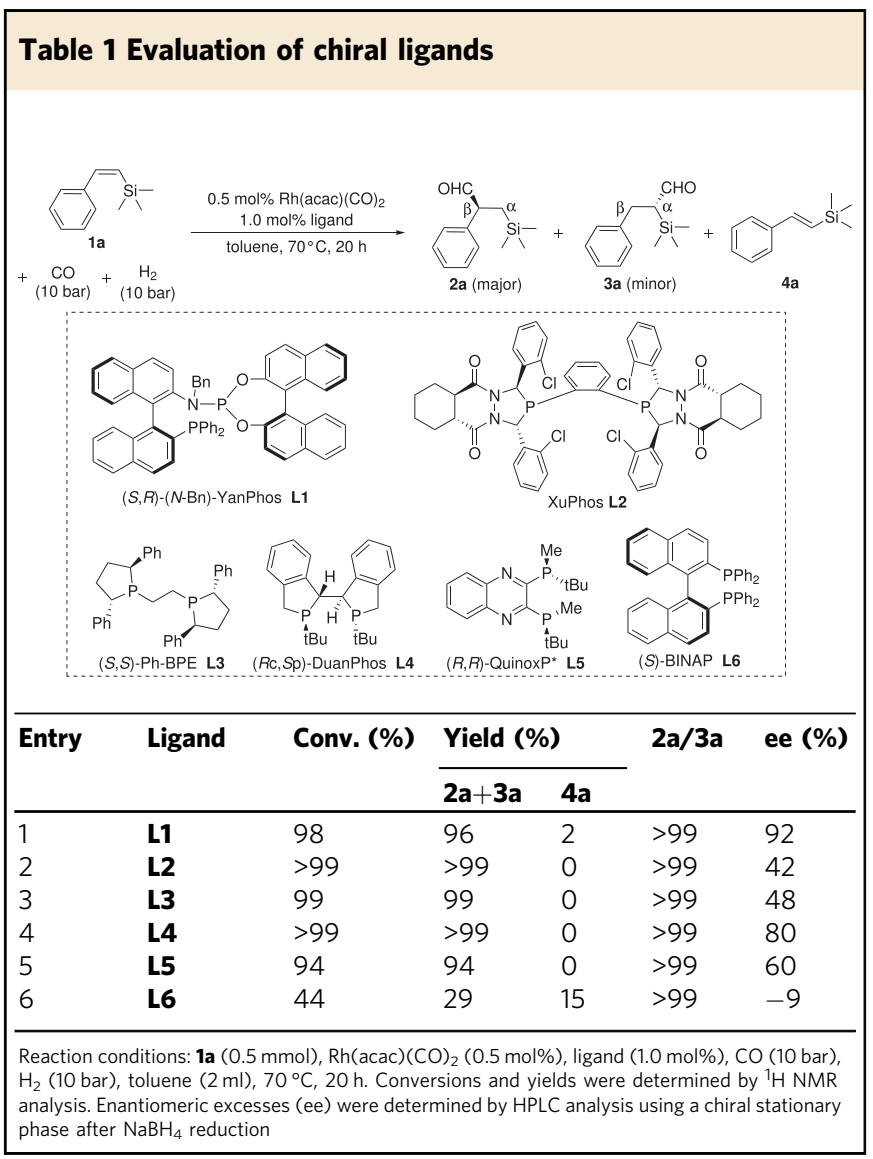

is a key element in many functional materials and bioactive molecules. Particularly, chiral $\beta$-aldehydesilanes are valuable intermediates, which can be readily converted to other versatile building blocks occurring in a variety of small molecule pharmaceuticals and natural products, such as drugs A (angiotensinconverting enzyme inhibitor), B (HIV protease inhibitor ${ }^{38}$, fasidotril $^{39}$, candoxatril ${ }^{40}$, venlafaxine ${ }^{41}$, tropicamide ${ }^{42}$, and natural products scopolamine ${ }^{43,44}$ and anisodamine ${ }^{45}$ (Fig. 1c).

Herein, we report a rhodium-catalyzed regioselective and stereospecific hydroformylation of 1,2-disubstituted alkenylsilanes: CO can be mainly incorporated at the $\beta$ position (up to $>99 / 1$ regioselectivity), respectively, and the corresponding $\beta$ aldehydesilanes are obtained with excellent enantioselectivity (up to $97 \%$ enantiomeric excesses (ee)). The products can be useful synthetic platforms based on the various transformations of the aldehyde group and silicon group (transformations of the silicon include Fleming-Tamao oxidation ${ }^{35}$, Hiyama coupling ${ }^{46}$, Brook and retro-Brook rearrangements ${ }^{47,48}$ ).

\section{Results}

Investigation of chiral ligands. Our initial studies focused on the AHF of (Z)-trimethyl(styryl)silane (1a) to give the desired chiral aldehyde product $\mathbf{2 a}$, with the expectations of achieving a highly regioselective and enantioselective transformation. To our delight, when $(S, R)-(N-B n)-Y a n P h o s$ was employed, the reaction almost exclusively took place in the $\beta$ position (the ratio of $2 \mathbf{a} / \mathbf{3 a}$ is $>99$ ) to produce $2 \mathrm{a}$ with $92 \%$ ee and $96 \%$ yield (Table 1 , entry 1 ). As summarized in Table 1 , an evaluation of ligands revealed $(S, R)$ $(N-B n)-Y a n P h o s$ to be superior to all others tested (Table 1, entry 1 vs. entries 2-6). Rh catalysts based on other ligands, including XuPhos, $(S, S)$-Ph-BPE, (Rc,Sp)-DuanPhos, and $(R)$-QuinoxP*, exhibited high activity and excellent regioselectivity with low to

\section{Table 2 Optimization of the asymmetric hydroformylation} of $1 \mathrm{a}$

\begin{tabular}{|c|c|c|c|c|c|c|c|c|}
\hline \multirow[t]{2}{*}{ Entry } & \multirow[t]{2}{*}{ Solvent } & \multirow[t]{2}{*}{$x$} & \multirow[t]{2}{*}{$T\left({ }^{\circ} \mathrm{C}\right)$} & \multirow{2}{*}{$\begin{array}{l}\mathrm{CO} / \\
\mathrm{H}_{2} \\
\text { (bar) }\end{array}$} & \multirow{2}{*}{$\begin{array}{l}\text { Conv. } \\
\text { (\%) }\end{array}$} & \multicolumn{2}{|c|}{ Yield (\%) } & \multirow{2}{*}{$\begin{array}{l}\text { ee } \\
\text { (\%) }\end{array}$} \\
\hline & & & & & & $2 a+3 a$ & $4 a$ & \\
\hline 1 & Toluene & 1.0 & 70 & $10 / 10$ & 98 & 96 & 2 & 92 \\
\hline 2 & THF & 1.0 & 70 & $10 / 10$ & $>99$ & 35 & 65 & - \\
\hline 3 & $\mathrm{CH}_{2} \mathrm{Cl}_{2}$ & 1.0 & 70 & $10 / 10$ & 89 & 80 & 9 & 93 \\
\hline 4 & EtOAc & 1.0 & 70 & $10 / 10$ & $>99$ & 95 & 5 & 91 \\
\hline 5 & DCE & 1.0 & 70 & $10 / 10$ & $>99$ & 96 & 4 & 90 \\
\hline $6^{a}$ & Toluene & 0.6 & 70 & $10 / 10$ & $>99$ & 25 & 75 & - \\
\hline 7 & Toluene & 1.5 & 70 & $10 / 10$ & 98 & 90 & 8 & 94 \\
\hline 8 & Toluene & 1.5 & 70 & $5 / 5$ & $>99$ & 99 & 1 & 94 \\
\hline 9 & Toluene & 1.5 & 70 & $2 / 2$ & $>99$ & 99 & 1 & 94 \\
\hline 10 & Toluene & 1.5 & 70 & $\begin{array}{l}20 / \\
20\end{array}$ & 99 & 91 & 8 & 94 \\
\hline 11 & Toluene & 1.5 & 60 & $5 / 5$ & 93 & 82 & 11 & 96 \\
\hline 12 & Toluene & 1.5 & 80 & $5 / 5$ & $>99$ & 85 & 15 & 91 \\
\hline $\begin{array}{l}\text { reductior } \\
\text { a } \\
\mathbf{2} \mathbf{a} / \mathbf{3 a}=\end{array}$ & $\begin{array}{l}\text { and yield } \\
\text { e) were } \mathrm{de}\end{array}$ & 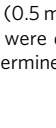 & م & & & & & $\begin{array}{l}\text { neric } \\
\mathrm{NaBH}\end{array}$ \\
\hline
\end{tabular}

good ee values, and almost no isomerization product was detected (Table 1, entries 2-5). (S)-BINAP, having axial chirality, was an unsatisfactory ligand for this reaction (Table 1, entry 6).

Investigation of reaction conditions. In order to achieve good regioselectivity and enantioselectivity and minimize the isomerization product $\mathbf{4 a}$, which was produced via the olefin insertion to the $\mathrm{Rh}-\mathrm{H}$ bond followed by $\beta$-hydride elimination, we sought to obtain optimal reaction conditions, as summarized in Table 2. We found that different solvents have an influence on the chemoselectivity, but a very small effect on the regioselectivity and enantioselectivity (Table 2, entries 1 and 3-5). Interestingly, when tetrahydrofuran was used, the olefin isomerization product 4a was obtained as the main product, which may be due to the solvent coordination effect (Table 2, entry 2). Next, the influence of the $\mathbf{L} 1 / \mathrm{Rh}$ ratio was investigated. Lowering of the $\mathrm{L} \mathbf{1} / \mathrm{Rh}$ ratio gave higher conversion, but the yield of the desired product $\mathbf{2 a}$ dropped significantly (Table 2 , entry 6 ). When the $\mathbf{L} 1 / \mathrm{Rh}$ ratio rose to 3 , higher enantioselectivity $(94 \%$ ee) with slightly lower yield ( $90 \%$ yield) was achieved (Table 2 , entry 7$)$. Under this ratio $(\mathbf{L} 1 / \mathrm{Rh}=3)$, the syngas pressure and reaction temperature were screened. The results indicated that lower syngas pressure and high temperature is beneficial to the conversion, which is consistent with the conclusion we have obtained for the YanPhos/Rh system (Table 2 , entries $7-12)^{15-19}$. The complete conversion was achieved in $20 \mathrm{~h}$ under 10 bar of $\mathrm{CO} / \mathrm{H}_{2}$ at $70{ }^{\circ} \mathrm{C}$, affording near quantitative yield of the desired product $2 \mathrm{a}$ with $94 \%$ ee (Table 2 , entry 8$)$. Lower pressure $\left(\mathrm{CO} / \mathrm{H}_{2}=2 / 2\right.$ bar $)$ was also tested, but no significant improvement was observed (Table 2, entry 9 vs. entry 8).

The study of isomerization reaction. To gain a deeper understanding of the relationship between syngas pressure and 
a

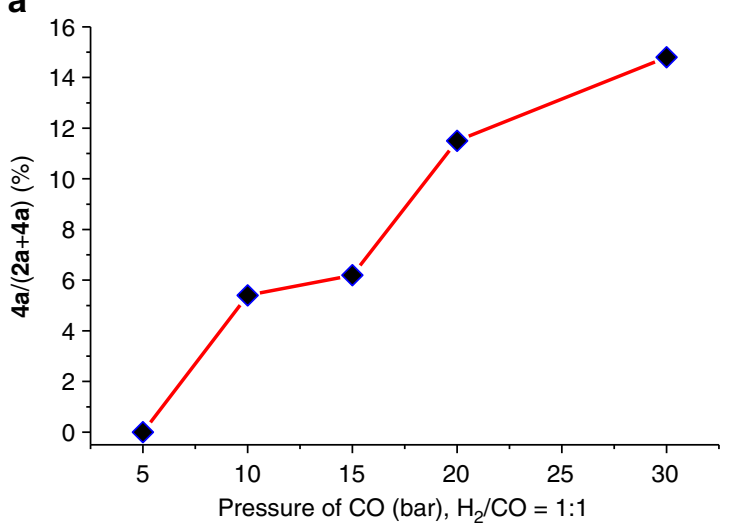

C

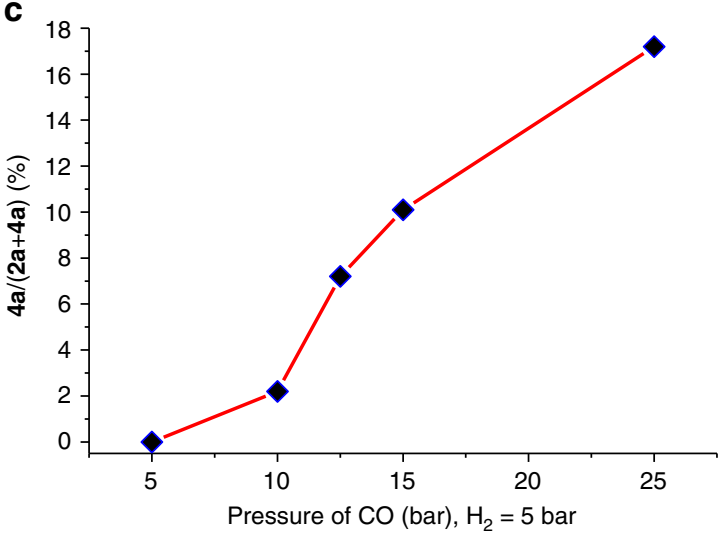

b

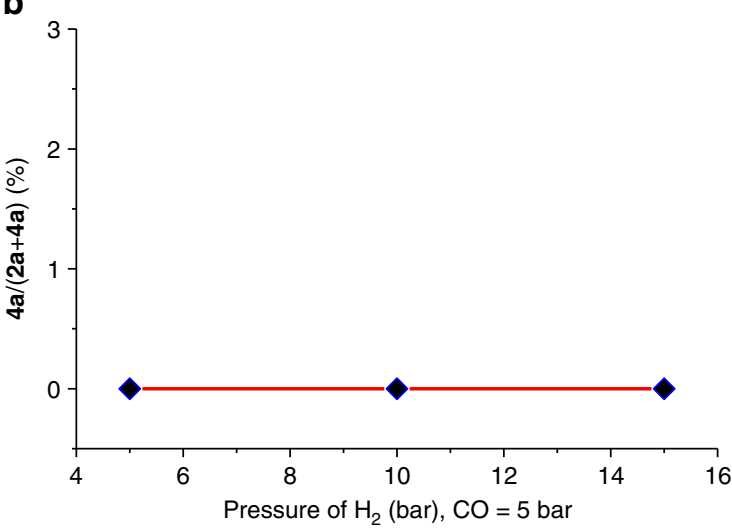

d<smiles>CS(=O)(=O)c1ccccc1</smiles>

A

$\downarrow$

$\mathrm{CHO}$

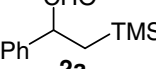

$2 a$

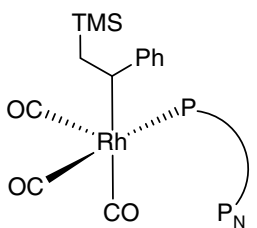

imination

$\mathrm{Ph}^{\curvearrowright}$ TMS

$4 a$

Fig. 2 Exploration of the isomerization reaction. a The relation between the isomerization and total pressure. $\mathbf{b}$ The effect of $\mathrm{H}_{2}$ partial pressure on the isomerization. c The effect of CO partial pressure on the isomerization. d A proposal for the isomerization reaction

isomerization, the effects of syngas $\left(\mathrm{CO} / \mathrm{H}_{2}=1: 1\right), \mathrm{H}_{2}$, and $\mathrm{CO}$ partial pressure on the isomerization were investigated systematically (Supplementary Table 1). Firstly, 4a was used as the substrate directly and very low conversion (only $1 \%$ ) was detected when the reactions were carried out in $20 \mathrm{~h}$ under $10 \mathrm{bar}$ of syngas $\left(\mathrm{CO} / \mathrm{H}_{2}=1: 1\right)$ at $70^{\circ} \mathrm{C}$ (Supplementary Table 1 , entry 1 ), which indicates that it is almost impossible to transform $\mathbf{4 a}$ under current catalytic system. We also stopped the reaction at about $50 \%$ conversion ( $2 \mathrm{a}$ was used as the substrate, $\mathrm{CO} / \mathrm{H}_{2}=5: 5 \mathrm{bar}$, $70{ }^{\circ} \mathrm{C}, 3.5 \mathrm{~h}$ ), but only trace $(<1 \%) \mathbf{4 a}$ was detected (Supplementary Table 1 , entry 2 ), which means that the isomerization is very slow at low pressure. As shown in Fig. 2a, the ratio of 4 a shows a strong dependence on the total syngas pressure $\left(\mathrm{CO} / \mathrm{H}_{2}=1: 1\right)$. To independently measure the effect of $\mathrm{H}_{2}$ partial pressure on the isomerization, one set of experiments used 5 bar $\mathrm{CO}$ pressure while varying $\mathrm{H}_{2}$ pressure from 5 to 15 bar. As shown in Fig. 2b, the ratio of $4 \mathbf{a}$ was almost unchanged as the $\mathrm{H}_{2}$ pressure varied. The independent measure of the effect of $\mathrm{CO}$ partial pressure was also carried out, the $\mathrm{H}_{2}$ pressure was held at constant 5 bar, and the $\mathrm{CO}$ partial pressure was varied from 5 to 25 bar. As shown in Fig. $2 \mathrm{c}$, raising the $\mathrm{CO}$ partial pressure could promote the isomerization, which is opposite to the results in previous papers ${ }^{49}$. We attempt to explain the problem from the mechanism, and proposed a proper path of the isomerization (Fig. 2d). Because of the competition between $\mathrm{CO}$ and the $\mathrm{P}_{\mathrm{N}}$ part of YanPhos for the rhodium center, $\mathbf{A}$ could convert to $\mathbf{B}$, which is critical for the isomerization. The coordination of $\mathrm{CO}$ to the rhodium species makes the Rh center of $\mathbf{B}$ electron deficient, which leads the $\mathrm{CO}$ on the equatorial position more weakly coordinated, while the $\mathrm{CO}$ on the axial position could not achieve the $\mathrm{CO}$ insertion. These properties of $\mathbf{B}$ may promote the $\beta$-hydride elimination to form $\mathbf{4} \mathbf{a}^{50}$. With the CO partial pressure increasing, $\mathbf{B}$ could be formed more easily, which leads to more isomerization.

Substrate scope. With the optimized conditions in hand, we explored the substrate scope and generality of this asymmetric transformation (Fig. 3). First, in order to investigate the influence of substituents on the silicon atom, we changed trimethylsilyl (1a) to dimethyl(phenyl)silyl (1b) and benzyldimethylsilyl (1c). We found that when $\mathbf{1 b}$ was employed as the substrate, the desired product $\mathbf{2 b}$ was obtained with excellent regioselectivity and enantioselectivity albeit with $80 \%$ yield. While, $2 \mathbf{c}$ was achieved in $96 \%$ yield with $97 \%$ ee and slightly lower regioselectivity $(\beta / \alpha=$ 97:3). Because of the simple preparation, trimethylsilyl was chosen as one substituent of the alkene, and a series of arylolefins were synthesized and investigated. Many functional groups, such as methyl (2d), methoxyl (2e), tertiary butyl (2f), phenyl (2g), trifluoromethyl (2j), and halides ( $2 \mathbf{h}$ and $\mathbf{2 i}$ ), are compatible with this transformation. It was found that, with electron-rich aryl alkenes, aldehyde products are formed in lower yields than that with electron-neutral and electron-deficient aryl alkenes. On the other hand, the regioselectivity and enantioselectivity are not obviously affected by the electrical properties of the benzene ring. Moreover, substrates with meta- or ortho- substitution on the phenyl group were readily accommodated $(2 \mathbf{k}-\mathbf{2 m})$. The highly electron-deficient substrate 1n was also well tolerated. Furthermore, good yields, regioselectivities, and enantioselectivities were obtained with a range of substrates containing other aromatic fragments, including napthalenes, furans, and thiophenes $(\mathbf{2 0 -}$ 2q). Then, more challenging substrates containing alkyl substituents were tested; to our delight, $2 \mathbf{r}$ and $2 \mathbf{s}$ were obtained with 


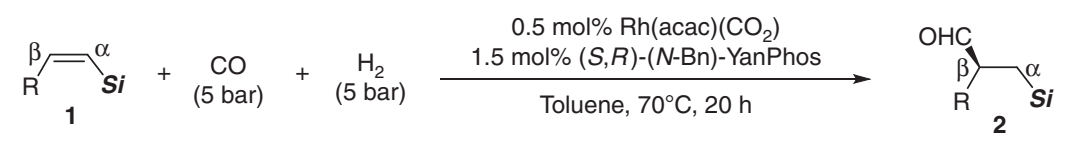

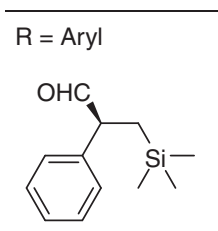

2a $96 \%$ yield $94 \%$ ee, $\beta / \alpha:>99$

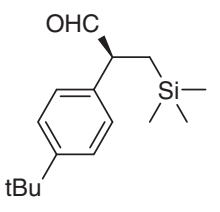

2f $85 \%$ yield $96 \%$ ee, $\beta / \alpha=99: 1$

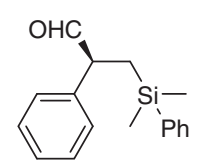

2b $80 \%$ yield $94 \%$ ee, $\beta / \alpha:>99$

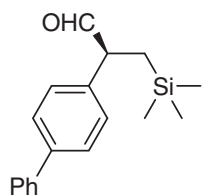

2g $95 \%$ yield $94 \%$ ee, $\beta / \alpha:>99$

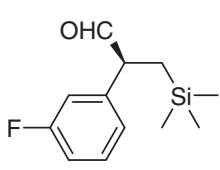

21 $97 \%$ yield $90 \%$ ee, $\beta / \alpha:>99$

2k 94\% yield 93\% ee, $\beta / \alpha: 96: 4$<smiles>C[Si](C)(C)C[C@@H](C=O)c1ccco1</smiles>

2p $94 \%$ yield 91\% ee, $\beta / \alpha$ : 95:5

$\mathrm{R}=\mathrm{Alkyl}$

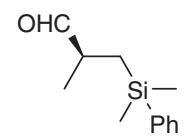

2r $94 \%$ yield

$94 \%$ ee, $\beta / \alpha=96: 4$

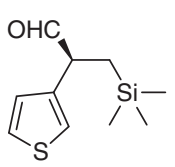

2q $89 \%$ yield 93\% ee, $\beta / \alpha: 97: 3$

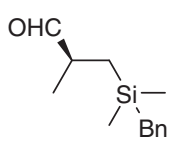

2s $92 \%$ yield $94 \%$ ee, $\beta / \alpha=94: 6$

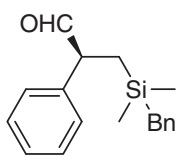

2c $96 \%$ yield $97 \%$ ee, $\beta / \alpha=97: 3$

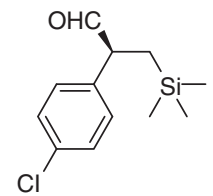

2h $97 \%$ yield 95\% ee, $\beta / \alpha$ : $>99$

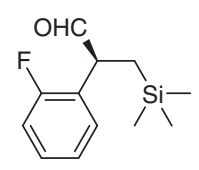

2m $90 \%$ yield $95 \%$ ee, $\beta / \alpha:>99$

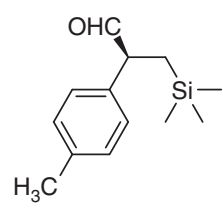

2d $88 \%$ yield $97 \%$ ee, $\beta / \alpha=95: 5$

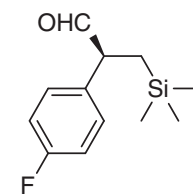

2i $96 \%$ yield $95 \%$ ee, $\beta / \alpha=97: 3$

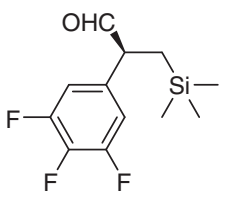

2n $98 \%$ yield $92 \%$ ee, $\beta / \alpha:>99$

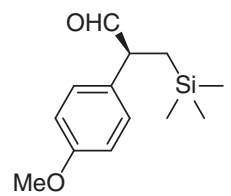

2e $86 \%$ yield $94 \%$ ee, $\beta / \alpha:>99$

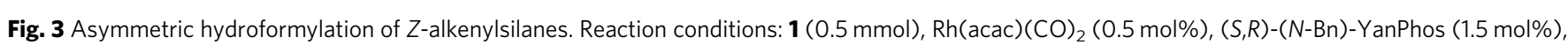
$\mathrm{CO}$ ( 5 bar), $\mathrm{H}_{2}\left(5\right.$ bar), toluene $(2 \mathrm{ml}), 70^{\circ} \mathrm{C}, 20 \mathrm{~h}$. Isolated yields. Product ratios were determined by ${ }^{1} \mathrm{H} \mathrm{NMR}$ analysis of the unpurified reaction mixture. Enantiomeric excesses (ee) were determined by HPLC analysis using a chiral stationary phase after $\mathrm{NaBH}_{4}$ reduction. ${ }^{\mathrm{a}} 1.0 \mathrm{~mol} \% \mathrm{Rh}($ acac$)(\mathrm{CO})_{2}$ and 3.0 mol\% $(S, R)-(N-B n)-Y a n P h o s$ were used

commendable results. And the compound 1t with larger steric hindrance could also be readily used albeit with $1 \mathrm{~mol} \%$ catalyst loading. By prolonging the chain length of the substituent, almost no effect on the reactivity was observed and excellent enantioselectivity $(95 \%$ ee) and good regioselectivity $(\beta / \alpha=92: 8)$ remained $(\mathbf{2 u})$. It should be pointed out that silyl enol ethers were not detected in the present system ${ }^{36,37}$.

To illustrate the critical role of the silane group, $Z$-alkenes bearing an alkyl group were tested (Fig. 4). The poor regioselectivity of $\mathbf{2 v}$ demonstrated that the hindered silicon groups, which facilitate the rhodium addition to the $\beta$ position in the olefin insertion step, are very critical for the regiocontrol. Moreover, when $\mathbf{1 w}$ was employed, almost no conversion was given. The low reaction activity of $\mathbf{1 v}$ and $\mathbf{1 w}$ implies an activating effect of the silicon groups in this transformation.
Mechanistic studies. On the basis of the previous computational and experimental results on other Rh-catalyzed hydroformylation $^{8,51-57}$, we also carried out DFT calculations (using $(S, R)-(N$ $\mathrm{Bn}$ )-YanPhos and 1a) to examine energetics of the whole reaction path for this Rh-catalyzed AHF and understand its regioselectivity and enantioselectivity to gain more insightful understanding (Figs. 5 and 6). As shown in Fig. 5, the alkene insertion step was computed to be the rate-determining step, which is in agreement with the previous computational studies ${ }^{51-56}$ and no observation of the H/D scrambling from the product (Fig. 7). In addition, as to the rate-determining step, $\mathbf{T S I}_{\mathbf{T M S}-\boldsymbol{\beta} \mathbf{1 R}}$ was computed to be lower in free energy than $\mathbf{T S I}_{\mathbf{T M S}-\boldsymbol{\alpha} \mathbf{1}}$ by $3.1 \mathrm{kcal} / \mathrm{mol}$ in solution (i.e., calculated $\beta / \alpha>99: 1$, Fig. $6 a$ and $b$ ), which is consistent with the experimental result. On the other hand, TSI $_{\text {TMS- } \mathbf{\beta 1 S}}$ is computed to be higher in free energy than TSI $_{\text {TMS- }}$ 


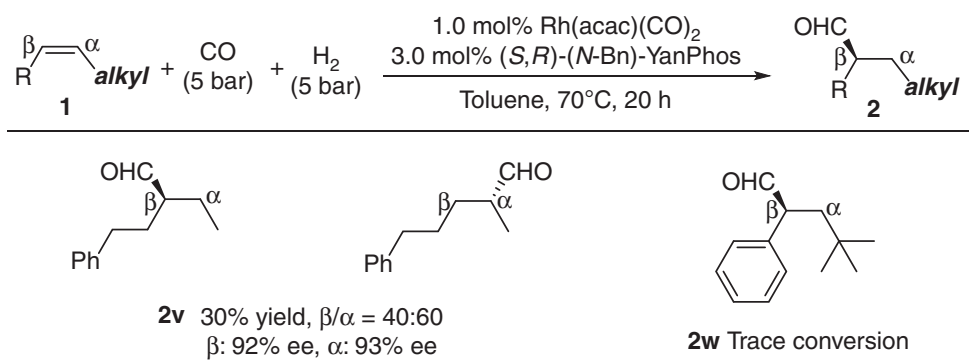

Fig. 4 Substrate effect. Reaction conditions: $1(0.5 \mathrm{mmol}), \mathrm{Rh}(\mathrm{acac})(\mathrm{CO})_{2}(1.0 \mathrm{~mol} \%),(\mathrm{S}, \mathrm{R})-(\mathrm{N}-\mathrm{Bn})-\mathrm{YanPhos}(3.0 \mathrm{~mol} \%), \mathrm{CO}(5 \mathrm{bar}), \mathrm{H}_{2}(5 \mathrm{bar})$, toluene $(2 \mathrm{ml}), 70^{\circ} \mathrm{C}, 20 \mathrm{~h}$. Yields and product ratios were determined by ${ }^{1} \mathrm{H}$ NMR analysis of the unpurified reaction mixture. Enantiomeric excesses (ee) were determined by HPLC analysis using a chiral stationary phase after $\mathrm{NaBH}_{4}$ reduction

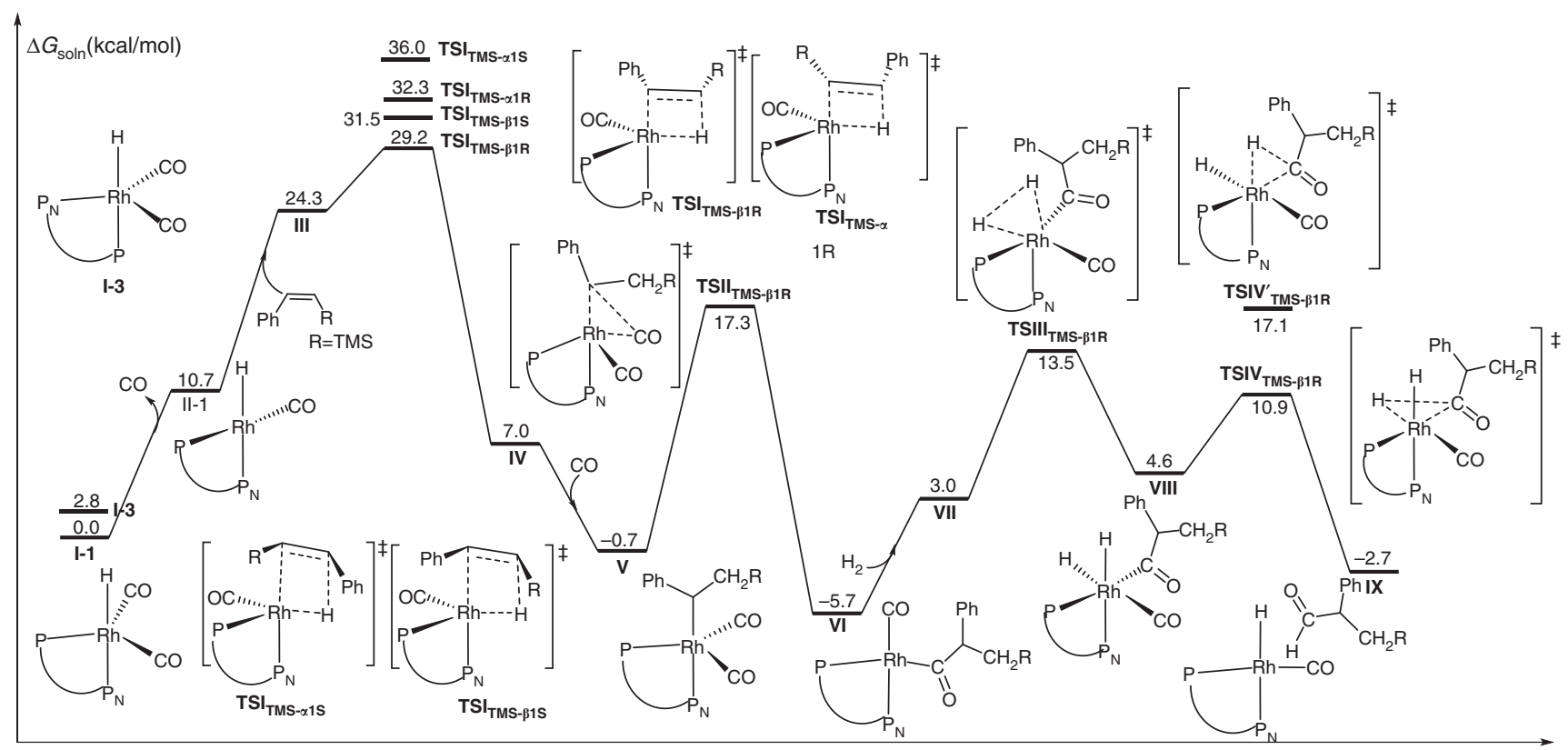

Fig. 5 Computation studies on the mechanism. The migratory insertion of Rh-H to alkene was computed to be the rate-determining step and determines the regioselectivity and enantioselectivity. TS, transition state

a

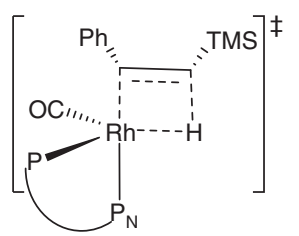

TSI $_{\text {TMS- } \beta 19}$ $\Delta G=29.2 \mathrm{kcal} / \mathrm{mol}$

C

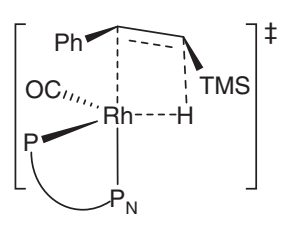

TSI $_{\text {TMS- } \beta 1 S}$ $\Delta G=31.5 \mathrm{kcal} / \mathrm{mol}$ b

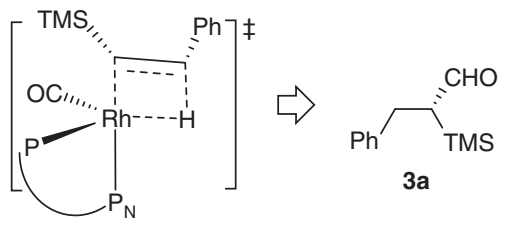

TSI $_{\text {TMS- } \alpha 1 R}$

$\Delta G=32.3 \mathrm{kcal} / \mathrm{mol}$

d<smiles>CC(C)C[C@@H](CO)C(C)C</smiles>

$\mathrm{TSI}_{\mathrm{tBu}-\beta 1 \mathrm{R}}$ $\Delta G=31.3 \mathrm{kcal} / \mathrm{mol}$

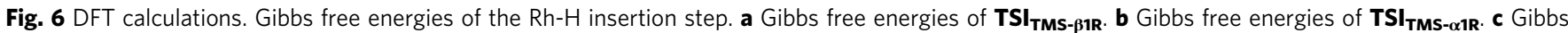

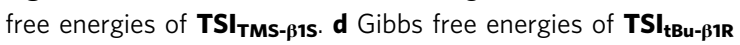




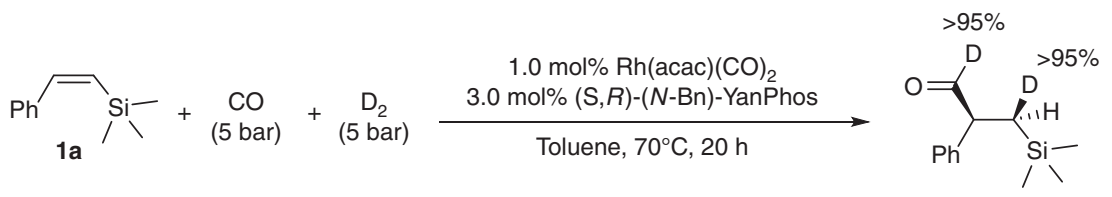

Fig. 7 Deuteration experiments. The $D$ incorporation in the products are $>95 \%$ according to ${ }^{1} \mathrm{H}$ NMR

a

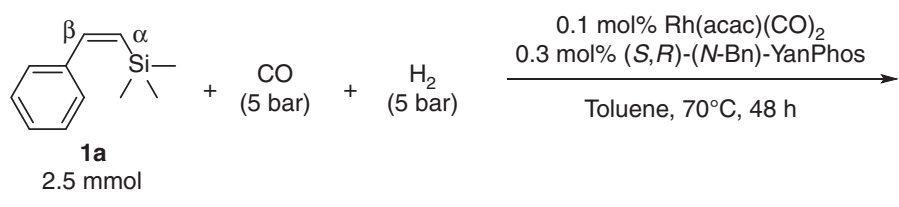

b

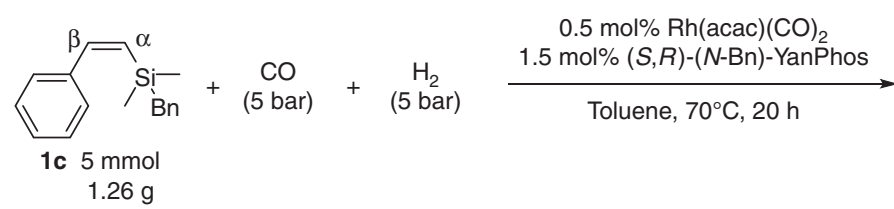

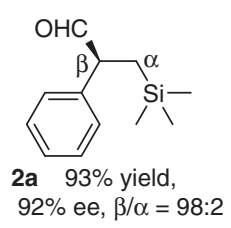

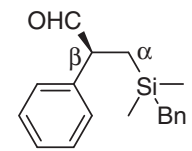

2c $1.34 \mathrm{~g}, 95 \%$ yield $96 \%$ ee, $\beta / \alpha=97: 3$

C

$\underset{1}{\mathrm{Si}-}+\underset{\mathrm{Bn}}{\mathrm{C} \text { bar })}+\underset{(5 \text { bar })}{\mathrm{H}_{2}} \stackrel{\text { As } \mathbf{b}}{\longrightarrow}$

1c $1 \mathrm{mmol}$

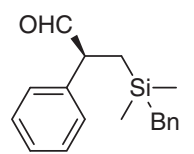

2c Not isolated
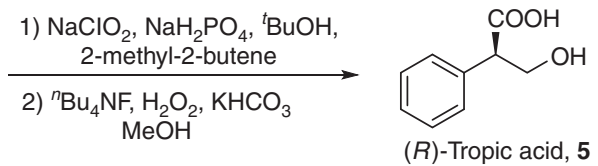

$74 \%$ yield from 1 c, $94 \%$ ee

Fig. 8 Synthetic applications of the asymmetric hydroformylation of Z-alkenylsilanes. a Asymmetric hydroformylation of $\mathbf{1 a}$ with $0.1 \mathrm{~mol} \% \mathrm{Rh}(\mathrm{acac})(\mathrm{CO})_{2}$. b Gram scale synthesis of 2c. c Synthesis of $(R)$-tropic acid

$\beta 1 \mathbf{R}$ by $2.3 \mathrm{kcal} / \mathrm{mol}$ in solution (i.e., calculated $98 \%$ ee, Fig. $6 \mathrm{a}$ and c), which is very close to the experimental result ( $94 \%$ ee). As shown in Fig. 6d, when $\mathbf{1 w}$ was used as the substrate, this transformation suffers from a higher barrier in the alkene insertion step, which qualitatively explains poor reactivity. Both the experimental results and computational results reveal that the silane group plays a critical role in this reaction, especially in the control of the regioselectivity and the activation of the substrate.

Applications of the transformation. To demonstrate the synthetic utility of the current methodology, the reaction was conducted with lower catalyst loading $(\mathrm{S} / \mathrm{C}=1000)$, affording the desired aldehyde 2 a in $93 \%$ yield with $92 \%$ ee and excellent regioselectivity (Fig. 8a). Gram scale reaction of 1 c could also proceed smoothly, and high yield, excellent regio- and enantioselectivity were remained (Fig. 8b). Furthermore, a creative synthetic route for chiral tropic acid which can be readily converted to tropicamide, hyoscyamine, scopolamine and anisodamine was developed $^{42,44}$. As shown in Fig. $8 \mathrm{c}$, the AHF product $2 \mathrm{c}$ was subjected to sequential oxidation of the aldehyde group and Fleming-Tamao oxidation to afford the desired enantiomerically enriched tropic acid 5 (94\% ee).

\section{Discussion}

In conclusion, we develop an efficient approach for synthesizing valuable chiral $\beta$-aldehydesilanes by catalytic AHF of $Z$-alkenylsilanes. Because of the hindered silicon groups, this transformation exhibits excellent regioselectivities $(\beta / \alpha$ up to $>99)$, and respectively, the corresponding $\beta$-aldehydesilanes are obtained with excellent enatioselectivities (up to 97\% ee) under mild reaction conditions with low catalyst loading. By using the transformations of aldehyde groups and silicon groups, the products can be useful synthetic intermediates for bioactive molecules and natural products. Moreover, experiment results and DFT calculations indicate that the silicon group are primary factors of the regiocontrol and substrates' reactivity in this asymmetric transformation.

\section{Methods}

General procedure for the AHF of alkenylsilanes. In a glovebox filled with nitrogen, to a $5 \mathrm{ml}$ vial equipped with a magnetic bar was added ligand $\mathbf{L 1}(0.0075$ $\mathrm{mmol})$ and $\mathrm{Rh}(\mathrm{acac})(\mathrm{CO})_{2}(0.0025 \mathrm{mmol}$ in $0.5 \mathrm{~mL}$ solvent). After stirring for 10 min, substrate $(0.5 \mathrm{mmol})$ and additional solvent were charged to bring the total volume of the reaction mixture to $2.0 \mathrm{~mL}$. The vial was transferred into an autoclave and taken out of the glovebox. Carbon monoxide ( 5 bar) and hydrogen (5 bar) were charged in sequence. The reaction mixture was stirred at $70^{\circ} \mathrm{C}$ (oil bath) for $20 \mathrm{~h}$. The reaction was cooled and the pressure was carefully released in a wellventilated hood. The conversion and $\beta / \alpha$ ratio were determined by ${ }^{1} \mathrm{H}$ NMR spectroscopy from the crude reaction mixture. Enantiomeric excesses (ee) were determined by HPLC analysis using a chiral stationary phase after $\mathrm{NaBH}_{4}$ reduction.

Data availability. The authors declare that the data supporting the conclusions of this study are available within the article and its Supplementary Information file or from the corresponding author upon reasonable request.

Received: 20 October 2017 Accepted: 17 April 2018 Published online: 23 May 2018

\section{References}

1. Agbossou, F., Carpentier, J. F. \& Mortreaux, A. Asymmetric hydroformylation. Chem. Rev. 95, 2485-2506 (1995).

2. Franke, R., Selent, D. \& Börner, A. Applied hydroformylation. Chem. Rev. 112, 5675-5732 (2012). 
3. Klosin, J. \& Landis, C. R. Ligands for practical rhodium-catalyzed asymmetric hydroformylation. Acc. Chem. Res. 40, 1251-1259 (2007).

4. Jia, X., Wang, Z., Xia, C. \& Ding, K. Recent advances in Rh-catalyzed asymmetric hydroformylation of olefins. Chin. J. Org. Chem. 33, 1369-1381 (2013).

5. Chikkali, S. H., van der Vlugt, J. I. \& Reek, J. N. H. Hybrid diphosphorus ligands in rhodium catalysed asymmetric hydroformylation. Coord. Chem. Rev. 262, 1-15 (2014).

6. Sakai, N., Mano, S., Nozaki, K. \& Takaya, H. Highly enantioselective hydroformylation of olefins catalyzed by new phosphine phosphite-rhodium (I) complexes. J. Am. Chem. Soc. 115, 7033-7034 (1993).

7. Sakai, N., Nozaki, K. \& Takaya, H. Asymmetric hydroformylation of 1,2disubstituted olefins catalysed by chiral phosphinephosphite-rhodium(I) complexes. J. Chem. Soc. Chem. Commun. 0, 395-396 (1994).

8. Nozaki, K. et al. Highly enantioselective hydroformylation of olefins catalyzed by rhodium(I) complexes of new chiral phosphine-phosphite ligands. J. Am. Chem. Soc. 119, 4413-4423 (1997).

9. Clark, T. P., Landis, C. R., Freed, S. L., Klosin, J. \& Abboud, K. A. Highly active, regioselective, and enantioselective hydroformylation with $\mathrm{Rh}$ catalysts ligated by bis-3,4-diazaphospholanes. J. Am. Chem. Soc. 127, 5040-5042 (2005).

10. McDonald, R. I., Wong, G. W., Neupane, R. P., Stahl, S. S. \& Landis, C. R. Enantioselective hydroformylation of $\mathrm{N}$-vinyl carboxamides, allyl carbamates, and allyl ethers using chiral diazaphospholane ligands. J. Am. Chem. Soc. 132, 14027-14029 (2010).

11. Abrams, M. L., Foarta, F. \& Landis, C. R. Asymmetric hydroformylation of Zenamides and enol esters with rhodium-bisdiazaphos catalysts. J. Am. Chem. Soc. 136, 14583-14588 (2014).

12. Nelsen, E. R., Brezny, A. C. \& Landis, C. R. Interception and characterization of catalyst species in rhodium bis(diazaphospholane)-catalyzed hydroformylation of octene, vinyl acetate, allyl cyanide, and 1-phenyl-1,3butadiene. J. Am. Chem. Soc. 137, 14208-14219 (2015).

13. Babin, J. E. \& Whiteker, G. T. Asymmetric syntheses. World patent WO1993003839 (1993).

14. Axtell, A. T. et al. Highly regio- and enantioselective asymmetric hydroformylation of olefins mediated by 2,5-disubstituted phospholane ligands. Angew. Chem. Int. Ed. 44, 5834-5838 (2005).

15. Yan, Y. \& Zhang, X. A hybrid phosphorus ligand for highly enantioselective asymmetric hydroformylation. J. Am. Chem. Soc. 128, 7198-7202 (2006)

16. Zhang, X. W., Cao, B. N., Yu, S. C. \& Zhang, X. M. Rhodium-catalyzed asymmetric hydroformylation of $N$-allylamides: highly enantioselective approach to $\beta^{2}$-amino aldehydes. Angew. Chem. Int. Ed. 49, 4047-4050 (2010).

17. Zhang, X. W. et al. Synthesis and application of modular phosphinephosphoramidite ligands in asymmetric hydroformylation: structureselectivity relationship. Chem. Eur. J. 16, 871-877 (2010).

18. You, C. et al. Rhodium-catalyzed desymmetrization by hydroformylation of cyclopentenes: synthesis of chiral carbocyclic nucleosides. Angew. Chem. Int. Ed. 55, 6511-6514 (2016).

19. Chen, C. et al. Rhodium/Yanphos-catalyzed asymmetric interrupted intramolecular hydroaminomethylation of trans-1,2-disubstituted alkenes. $J$. Am. Chem. Soc. 138, 9017-9020 (2016).

20. Lightburn, T. E., Dombrowski, M. T. \& Tan, K. L. Catalytic scaffolding ligands: an efficient strategy for directing reactions. J. Am. Chem. Soc. 130, 9210-9211 (2008).

21. Worthy, A. D., Joe, C. L., Lightburn, T. E. \& Tan, K. L. Application of a chiral scaffolding ligand in catalytic enantioselective hydroformylation. J. Am. Chem. Soc. 132, 14757-14759 (2010).

22. Joe, C. L., Blaisdell, T. P., Geoghan, A. F. \& Tan, K. L. Distal-selective hydroformylation using scaffolding catalysis. J. Am. Chem. Soc. 136, 8556-8559 (2014).

23. Noonan, G. M., Fuentes, J. A., Cobley, C. J. \& Clarke, M. L. An asymmetric hydroformylation catalyst that delivers branched aldehydes from alkyl alkenes. Angew. Chem. Int. Ed. 51, 2477-2480 (2012).

24. Breit, B. \& Breuninger, D. Desymmetrizing hydroformylation with the aid of a planar chiral catalyst-directing group. J. Am. Chem. Soc. 126, 10244-10245 (2004).

25. Grünanger, C. U. \& Breit, B. Remote control of regio- and diastereoselectivity in the hydroformylation of bishomoallylic alcohols with catalytic amounts of a reversibly bound directing group. Angew. Chem. Int. Ed. 49, 967-970 (2010).

26. Kuil, M., Goudriaan, P. E., Piet, W. N. M., van Leeuwen, P. W. N. M. \& Reek, J. N. H. Template-induced formation of heterobidentate ligands and their application in the asymmetric hydroformylation of styrene. Chem. Commun. 45, 4679-4681 (2006).

27. Gadzikwa, T., Bellini, R., Dekker, H. L. \& Reek, J. N. H. Self-assembly of a confined rhodium catalyst for asymmetric hydroformylation of unfunctionalized internal alkenes. J. Am. Chem. Soc. 134, 2860-2863 (2012).
28. Chikkali, S. H., Bellini, R., de Bruin, B., van der Vlugt, J. I. \& Reek, J. N. H. Highly selective asymmetric Rh-catalyzed hydroformylation of heterocyclic olefins. J. Am. Chem. Soc. 134, 6607-6616 (2012).

29. Zhao, B., Peng, X., Wang, W., Xia, C. \& Ding, K. Modular chiral bidentate phosphonites: design, synthesis, and application in catalytic asymmetric hydroformylation reactions. Chem. Eur. J. 14, 7847-7857 (2008).

30. Breeden, S., Cole-Hamilton, D. J., Foster, D. F., Schwarz, G. J. \& Wills, M. Rhodium-mediated asymmetric hydroformylation with a novel bis (diazaphospholidine) ligand. Angew. Chem. Int. Ed. 39, 4106-4108 (2000).

31. Schmitz, C., Holthusen, K. \& Leitner, W. \& Franciò, G. Highly regio- and enantioselective hydroformylation of vinyl esters using bidentate phosphine, P-chiral phosphorodiamidite ligands. ACS Catal. 6, 1584-1589 (2016).

32. Mon, I., Jose, D. A. \& Vidal-Ferran, A. Bis(phosphite) ligands with distal regulation: application in rhodium-mediated asymmetric hydroformylations. Chem. Eur. J. 19, 2720-2725 (2013)

33. Fernández-Pérez, H., Benet-Buchholz, J. \& Vidal-Ferran, A. Enantiopure narrow bite-angle P-OP ligands: synthesis and catalytic performance in asymmetric hydroformylations and hydrogenations. Chem. Eur. J. 20, 15375-15384 (2014)

34. Vidal-Ferran, A., Mon, I., Bauzá, A., Frontera, A. \& Rovira, L. Supramolecularly regulated ligands for asymmetric hydroformylations and hydrogenations. Chem. Eur. J. 21, 11417-11426 (2015).

35. Kubota, K., Yamamoto, E. \& Ito, H. Regio- and enantioselective monoborylation of alkenylsilanes catalyzed by an electron-donating chiral phosphine-copper(I) complex. Adv. Synth. Catal. 355, 3527-3531 (2013).

36. Doyle, M. M., Jackson, W. R. \& Perlmutter, P. Regioselection in the hydroformylation of t-butyldiphenyl-silylalkenes: a new approach to aldol synthesis. Tetrahedron Lett. 30, 233-234 (1989).

37. Doyle, M. M., Jackson, W. R. \& Perlmutter, P. The stereochemistry of organometallic compounds. XXXIV. regioselection in the hydroformylation of silylalkenes. Aust. J. Chem. 42, 1907-1918 (1989).

38. Franz, A. K. \& Wilson, S. O. Organosilicon molecules with medicinal applications. J. Med. Chem. 56, 388-405 (2013).

39. Bralet, J., Marie, C., Gros, C., Schwartz, J. C. \& Lecomte, J. M. Fasidotril: the 1st dual inhibitor of neprilysin and ACE. Cardiovasc. Drug Rev. 18, 1-24 (2000).

40. James, K. et al. Inhibitors of neutral endopeptidase 24.11, a zinc-dependent protease involved in the degradation of a trial natriuretic factor. Perspect. Med. Chem. 4, 45-60 (1993).

41. Golden, R. N. \& Nicholas, L. Antidepressant efficacy of venlafaxine. Depress Anxiety 12, 45-49 (2000)

42. Dei, S., Bellucci, C., Ghelardini, C., Romanelli, M. N. \& Spampinato, S. Synthesis, characterization and pharmacological profile of tropicamide enantiomers. Life Sci. 58, 2147-2153 (1996).

43. Leete, E. Recent developments in the biosynthesis of the tropane alkaloids Planta Med. 56, 339-352 (1990).

44. Li, Y. A method for synthesis of scopolamine and its salts. Chinese patent CN 104628718 (2015).

45. Munoz, M. A., Munoz, O. \& Joseph-Nathan, P. Absolute configuration of natural diastereoisomers of $6 \beta$-hydroxyhyoscyamine by vibrational circular dichroism. J. Nat. Prod. 69, 1335-1340 (2006).

46. Komiyama, T., Minami, Y. \& Hiyama, T. Recent advances in transition-metalcatalyzed synthetic transformations of organosilicon reagents. ACS Catal. 7, 631-651 (2017).

47. Hudrlik, P. F., Hudrlik, A. M. \& Kulkarni, A. K. Protodesilylation reactions of simple $\beta$-hydroxysilanes (and $\alpha$-hydroxysilanes) homo-brook rearrangements. J. Am. Chem. Soc. 104, 6809-6811 (1982).

48. Hashimoto, R., Iida, T., Aikawa, K., Ito, S. \& Mikami, K. Direct asiladifluoromethylation of lithium enolates with Ruppert-Prakash reagent via C-F bond activation. Chem. Eur. J. 20, 2750-2754 (2014).

49. Watkins., A. L. \& Landis, C. R. Origin of pressure effects on regioselectivity and enantioselectivity in the rhodium-catalyzed hydroformylation of styrene with (S,S,S)-BisDiazaphos. J. Am. Chem. Soc. 132, 10306-10317 (2010).

50. Vilches-Herrera, M., Domke, L. \& Börner, A. Isomerization-hydroformylation tandem reactions. ACS Catal. 4, 1706-1724 (2014).

51. Lei, M., Wang, Z., Du, X., Zhang, X. \& Tang, Y. Asymmetric hydroformylation catalyzed by $\mathrm{RhH}(\mathrm{CO})_{2}[(\mathrm{R}, \mathrm{S})$-Yanphos]: mechanism and origin of enantioselectivity. J. Phys. Chem. A 118, 8960-8970 (2014).

52. Aguado-Ullate, S., Saureu, S., Guasch, L. \& Carbó, J. J. Theoretical studies of asymmetric hydroformylation using the Rh-(R,S)-BINAPHOS catalystorigin of coordination preferences and stereoinduction. Chem. Eur. J. 18, 995-1005 (2012).

53. Jacobs, I., de Bruin, B. \& N. H. Reek, J. Comparison of the full catalytic cycle of hydroformylation mediated by mono- and bis-ligated triphenylphosphinerhodium complexes by using DFT calculations. ChemCatChem 7, 1708-1718 (2015).

54. Gellrich, U., Himmel, D., Meuwly, M. \& Breit, B. Realistic energy surfaces for real-world systems: an IMOMO CCSD(T):DFT scheme for rhodium-catalyzed 
hydroformylation with the 6-DPPon ligand. Chem. Eur. J. 19, 16272-16281 (2013).

55. Kégl, T. Computational aspects of hydroformylation. RSC Adv. 5, 4304-4327 (2015).

56. Dingwall, P. et al. Understanding a hydroformylation catalyst that produces branched aldehydes from alkyl alkenes. J. Am. Chem. Soc. 139, 15921-15932 (2017).

57. Castillo Molina, D. A. et al. Studies establish the presence of a second equatorial-apical isomer of $[(R, S)$-Binaphos $](\mathrm{CO})_{2} \mathrm{RhH}$. Organometallics 29, 3362-3367 (2010).

\section{Acknowledgements}

We are grateful for financial support from the National Natural Science Foundation of China (Grant Nos 21402145, 21432007, and 21372179), the Youth Chen-Guang Science and Technology Project of Wuhan City (2015071704011640), the Natural Science Foundation of Hubei Province (2014CFB181), the Fundamental Research Funds for Central Universities (2042017kf0177), the Important Sci-Tech Innovative Project of Hubei Province (2015ACA058), and the "111" Project of the Ministry of Education of China.

\section{Author contributions}

C.Y. and X.L. contributed equally to this work. C.Y. and X.L. contributed to the conception and design of the experiments. C.Y., X.L., Y.-S.Y., S.L., and B.W. performed the experiments and analyzed the data. X.T. carried out the deuterium labeling experiment. Y.Y. and L.W.C. carried out the computations. C.Y. and H.L. wrote the manuscript with feedback and guidance from X.Z. H.L. and X.Z. directed the project. All authors discussed the experimental results and commented on the manuscript.

\section{Additional information}

Supplementary Information accompanies this paper at https://doi.org/10.1038/s41467018-04277-7.

Competing interests: The authors declare no competing interests.

Reprints and permission information is available online at http://npg.nature.com/ reprintsandpermissions/

Publisher's note: Springer Nature remains neutral with regard to jurisdictional claims in published maps and institutional affiliations.

(c) Open Access This article is licensed under a Creative Commons Attribution 4.0 International License, which permits use, sharing, adaptation, distribution and reproduction in any medium or format, as long as you give appropriate credit to the original author(s) and the source, provide a link to the Creative Commons license, and indicate if changes were made. The images or other third party material in this article are included in the article's Creative Commons license, unless indicated otherwise in a credit line to the material. If material is not included in the article's Creative Commons license and your intended use is not permitted by statutory regulation or exceeds the permitted use, you will need to obtain permission directly from the copyright holder. To view a copy of this license, visit http://creativecommons.org/ licenses/by/4.0/.

(C) The Author(s) 2018 